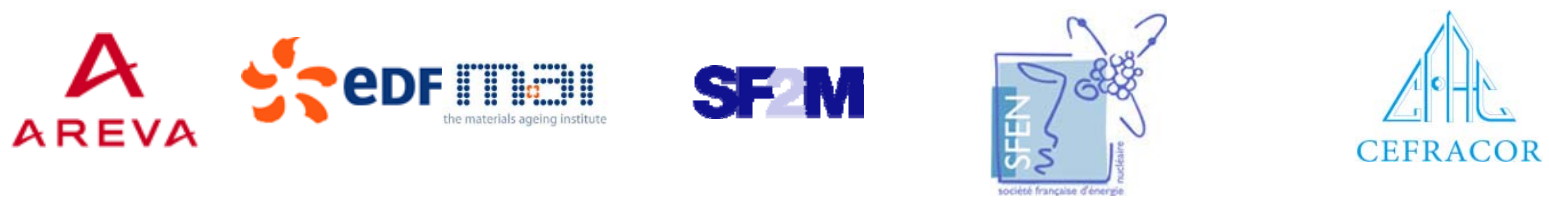

\section{MIN口S}

Centre of Excellence for Nuclear Materials

\section{Workshop}

Materials Innovation for Nuclear Optimized Systems
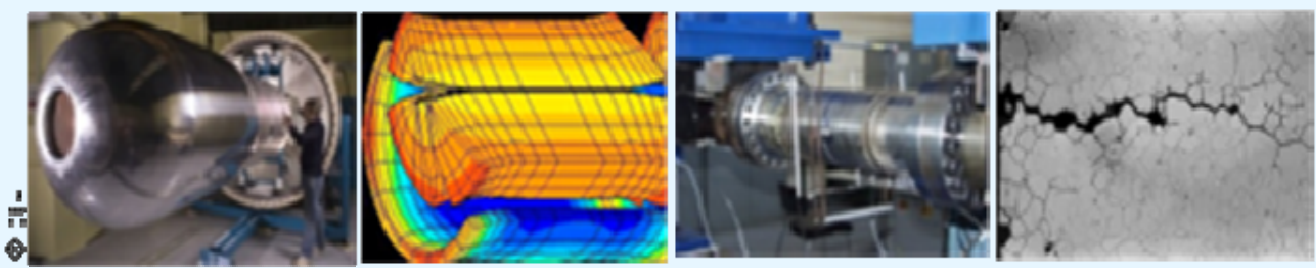

December 5-7, 2012, CEA - INSTN Saclay, France

\section{Christophe VALOT et al. \\ CEA (France)}

Post-Irradiation Analysis of Fission Gases in Nuclear Fuels

Workshop organized by:

Christophe GALLÉ, CEA/MINOS, Saclay - christophe.galle@cea.fr Constantin MEIS, CEA/INSTN, Saclay - constantin.meis@cea.fr 
MIN口S

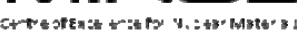

Workshop Materials Innovation for Nuclear Optimized Systems December 5-7, 2012, CEA - INSTN Saclay, France

\title{
Post-Irradiation Analysis of Fission Gases in Nuclear Fuels
}

\author{
Christophe VALOT ${ }^{1}$, Jean NOIROT ${ }^{1}$, Yves PONTILLON ${ }^{1}$ \\ ${ }^{1}$ CEA-DEN-DEC, Service d'Analyse et de Caractérisation du Comportement des Combustibles, SA3C (Cadarache, France)
}

Researches about irradiated fuel are conducted in order to investigate fuel properties and fuel behavior. These works cover various nuclear fuel operating conditions (i.e. Nominal operating conditions, off normal and severe accidents conditions, storage conditions...). Experimental investigations may be carried out through hot cell characterization and/or analytical tests [1-3], (Fig. 1). This talk is focused on the Fission Gas (FG) behavior which is a leading parameter in the overall fuel rod performance. Several parameters promote fission gas release (FGR) from nuclear fuels. Temperature is the most important one, but the local fuel microstructure has also to be considered as a key parameter. With the increase in fuel burn-up, the formation of a FG rich microstructure socalled High Burn-up Structure (HBS) has been evidenced in the fuel pellet periphery. Thus, it is a key issue to assess the contribution of the different parts of the fuel pellet to the total FGR using PostIrradiation analyses.

Through an example of experimental program performed on a standard $\mathrm{PWR} \mathrm{UO}_{2}$ fuel, the benefits of a coupled approach "Post-Irradiation analyses" and "out-of-pile annealing test" is shown.

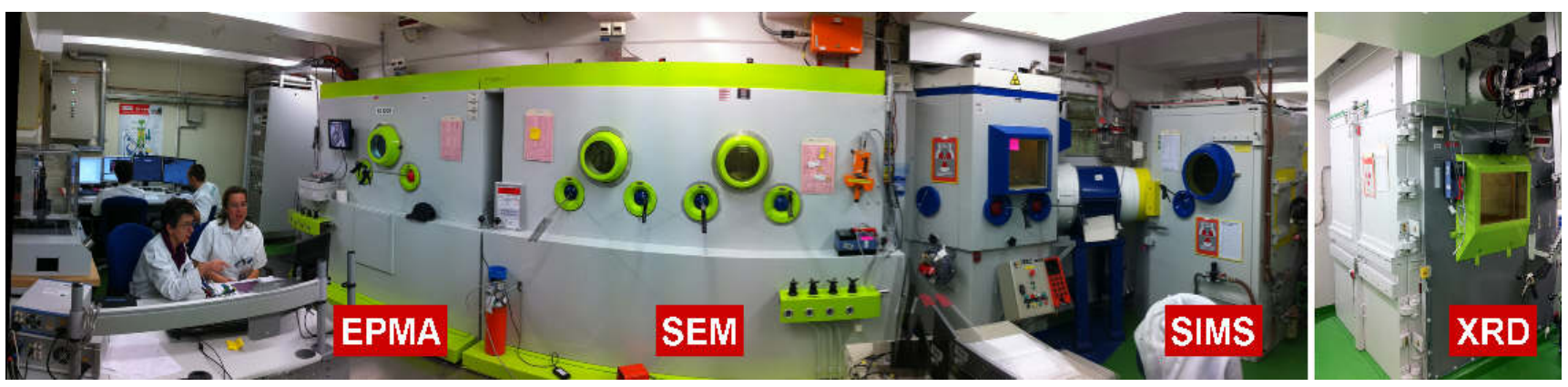

(a)

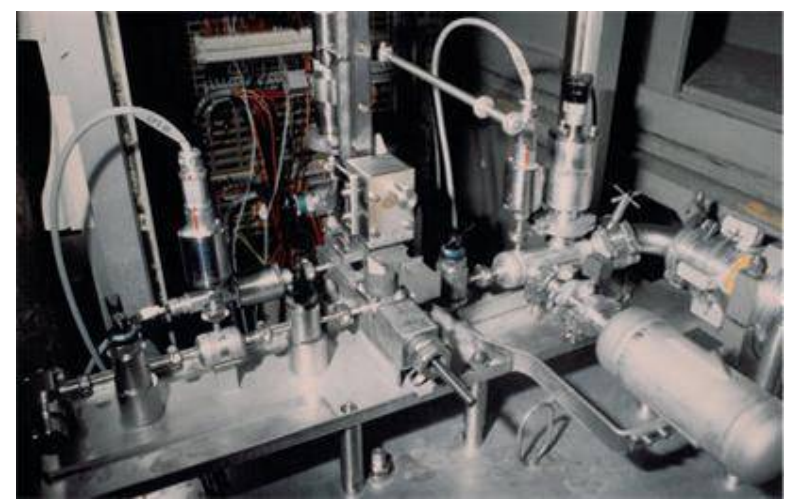

(b)

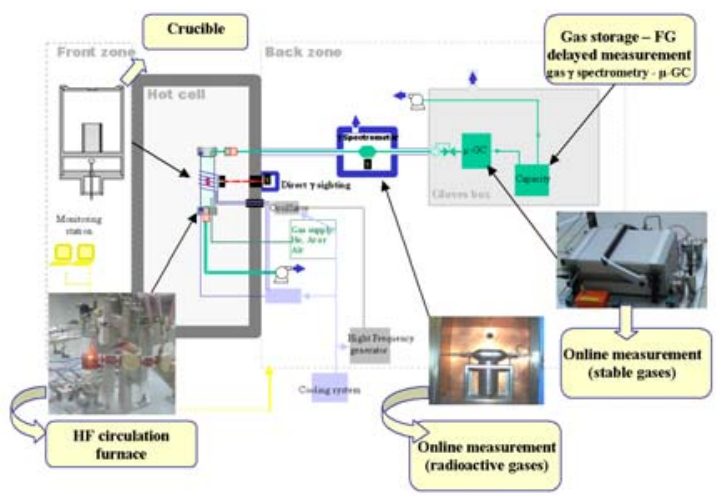

(c)

Fig. 1: LECA-STAR Hot-cell capabilities; (a) $\mu$-analysis laboratory; (b) puncturing facility; (c) Annealing tests facility (MERARG II). 


\section{References}

[1] J. Noirot et al., LWR fuel gas characterization at CEA Cadarache LECA-STAR Hot Laboratory. Post-Irradiation Examination and In-Pile Measurement Techniques for Water Reactor Fuels, IAEATECDOC-CD-1635-2009.

[2] J. Noirot et al., High burnup changes in UO2 fuels irradiated up to $83 \mathrm{GWd} / \mathrm{t}$ in $\mathrm{M} 5{ }^{\circledR}$ claddings. Journal of Nuclear Engineering and Technology, Vol. 41, n²-3 (2009).

[3] Y. Pontillon et al., Experimental and Theoretical Investigation of Fission Gas Release from UO2 up to $70 \mathrm{GWd} / \mathrm{t}$ under Simulated LOCA type Conditions: the GASPARD Program. Proceeding of the 2004 International Meeting on LWR Fuel Performance, Orlando, Florida, September 19-22, 2004. 
DE LA RECHERCHE À L'INDUSTRIE

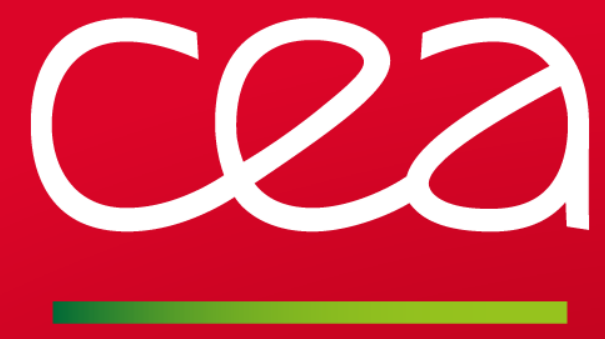

\section{Post-Irradiation analysis of fission gases in nuclear fuels}

Ch. VALOT, J. NOIROT, Y. PONTILLON

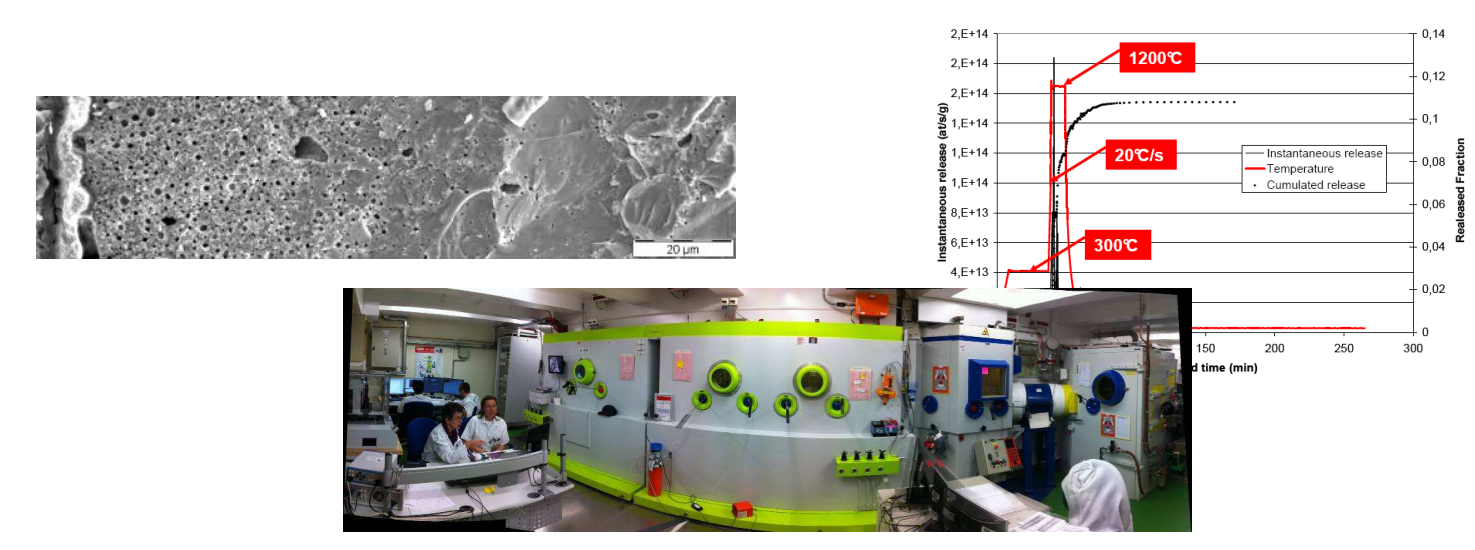

MINOS Workshop, Materials Innovation for Nuclear Optimized Systems December 5-7, 2012, CEA - INSTN Saclay, France 


\section{cea Outline}

\section{MINDS}

- Fission gases in LWR: a safety issue

- PIE facilities

Eission gases behavior: nominal operating conditions

- Fission gases behavior: simulated accidental conditions

- Further projects 


\section{Cea Fission gas a safety issue in Light Water Reactor}

\section{MIN口S}

I. Industrial issue

- Safety criterion : Internal cladding pressure at fuel rods end of life

- Scientific needs

- Fission gases Formation/Evolution...

- Nano-scale bubbles formation

- From nano-scale to micro-scale

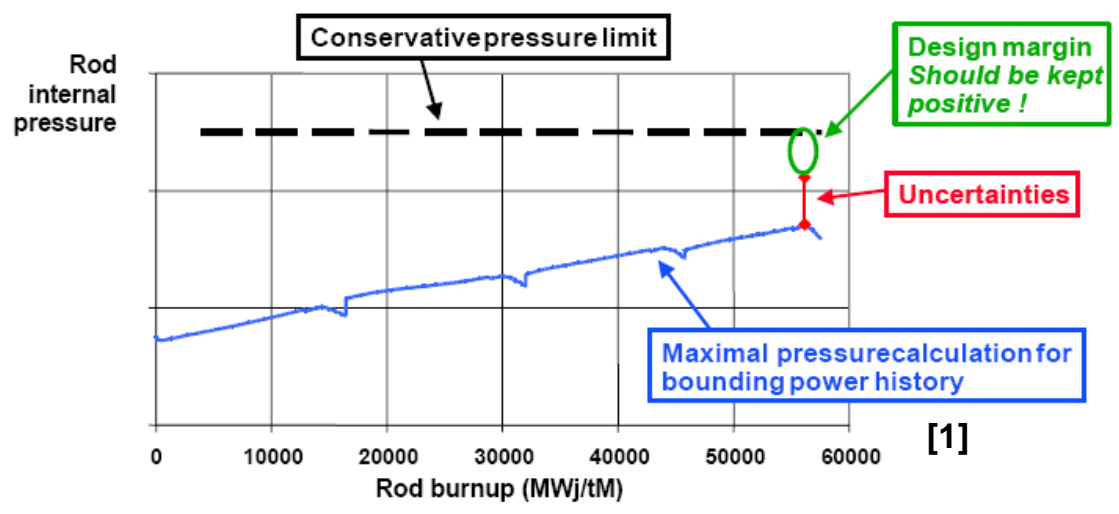
bubbles

- Fission gases features (bubbles internal pressure)

- Fission gases vs. fuel microstructure

- Link between fission gas release and fuel $\mu$ structure

- Fission gases involved in the HBS (High Burnup Structure) formation

- Gas release from HBS (normal and off-normal conditions)

[1]: B. Petitprez, B. Delaye, S. Beguin

Proceedings of EHPGM Enlarged Halden Project Group Meeting, Lillehammer 2005

[2]: Ch. Valot, J. Noirot, Y. Pontillon

Séminaire MINOS, 12-13 Septembre 2011, Saclay, Neurospin

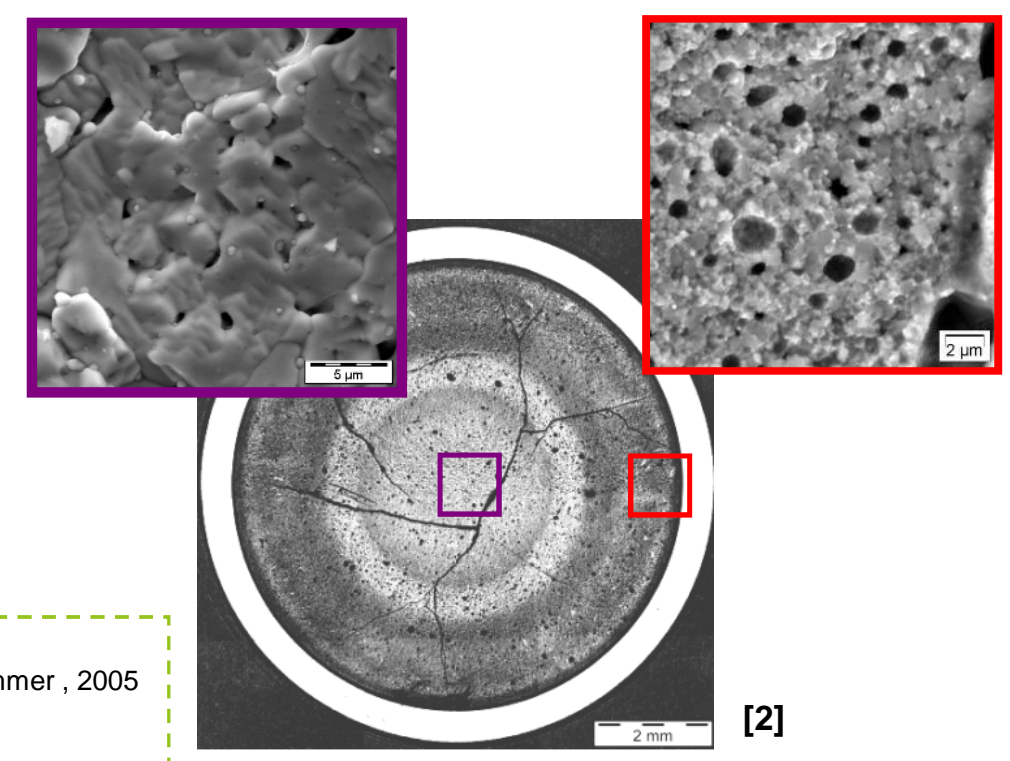




\section{cea Outline}

\section{MINDS}

\section{(1)}

\section{PIE facilities}

(

I

$\square$ 


\section{Post-Irradiation Analyses: Cadarache LECA-STAR Hot Laboratory}

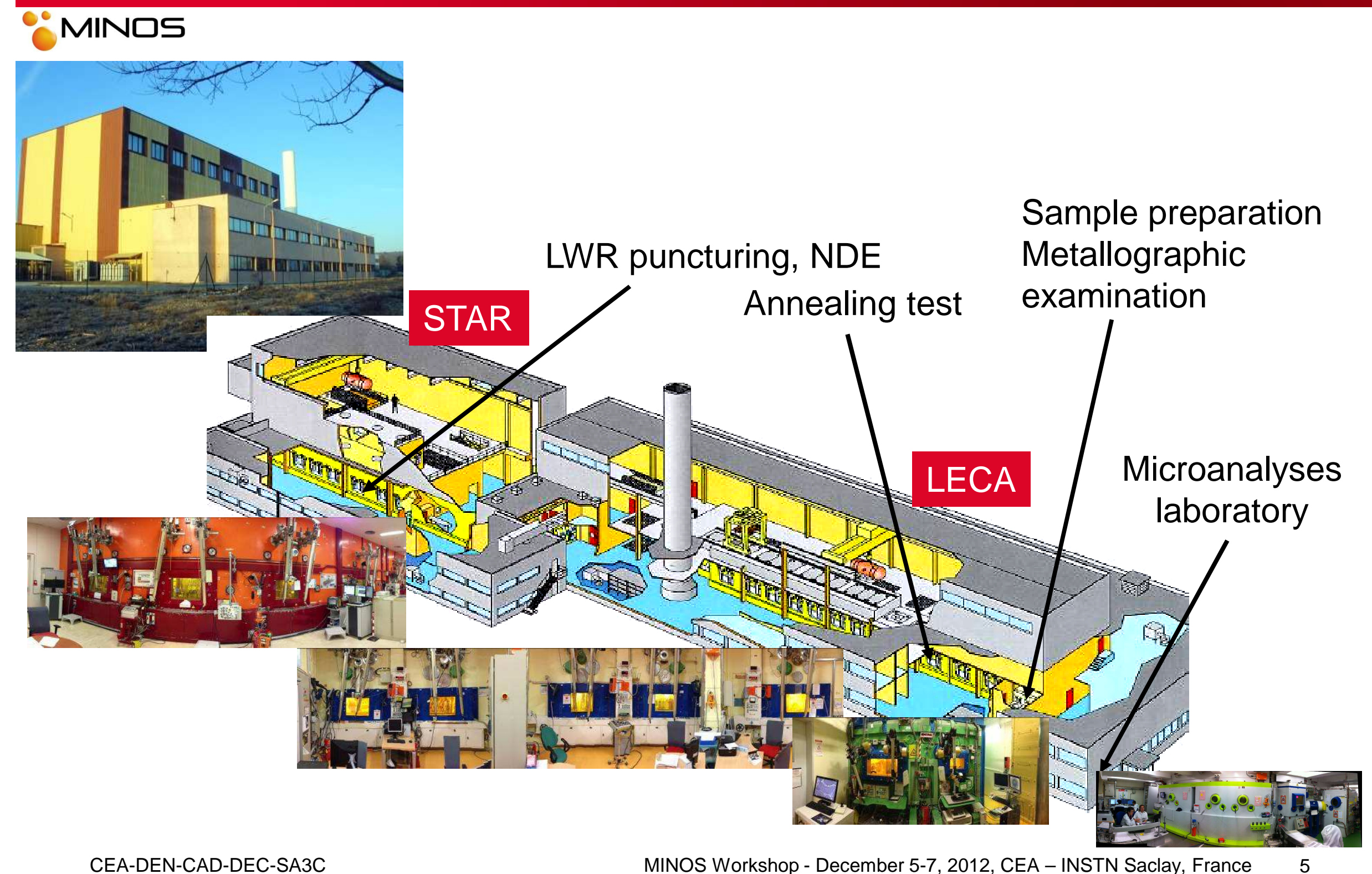




\section{Cea Out of Pile annealing capabilities}

\section{MIN口S}

- Experimental objectives:

- Better understanding of fuel behavior under nominal condition,

- Out of Pile simulation of fission gas release in case of accidental conditions (LOCA or RIA)

- Device capabilities:

- Sampling: 10-20 mm segment

- High Frequency induction furnace:

- Max. Temp.: $2800^{\circ} \mathrm{C}$

- Max. Temp. ramp: $200^{\circ} \mathrm{C} / \mathrm{s}$

- Accurate temperature monitoring

- Fission gas analysis:

- Gamma spectrometry for online measurement

- Gas-chromatography for stable gas analysis ( $\mathrm{He} . .$.

[3]: J. Noirot, Ch. Gonnier, L. Desgranges, Y. Pontillon, J. Lamontagne

IAEA-TECDOC-CD-1635-2009

[4]: Y. Pontillon et al.

Proc. Of the 2004 International Meeting on LWR Fuel Performance, Orlando, Florida, September 1-22, 2004

\section{Annealing device principle ${ }_{[3,4]}$}

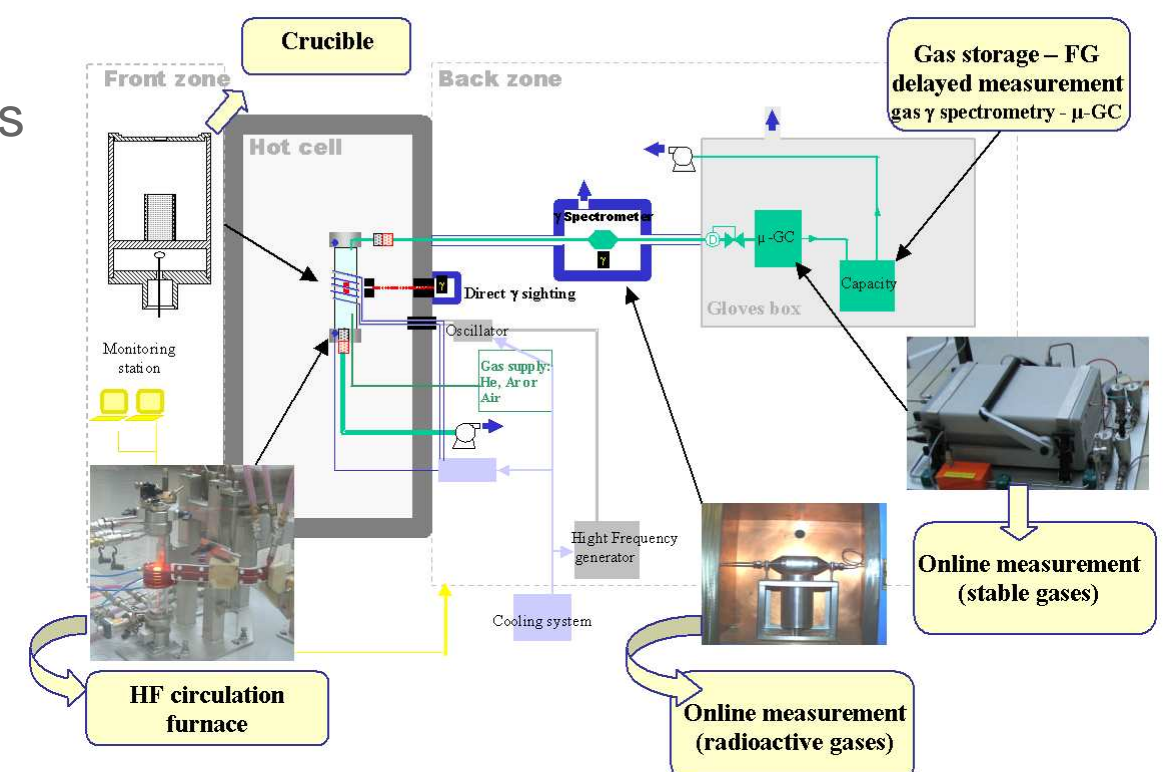
CEA-DEN-CAD-DEC-SA3C 


\section{Cea Post Irradiation Examination capabilities}

¿MINDS

Actinides and FP:

- Location

- Quantification

Euel microstructure:

- Porosity, HBS...

- Crystalline structure
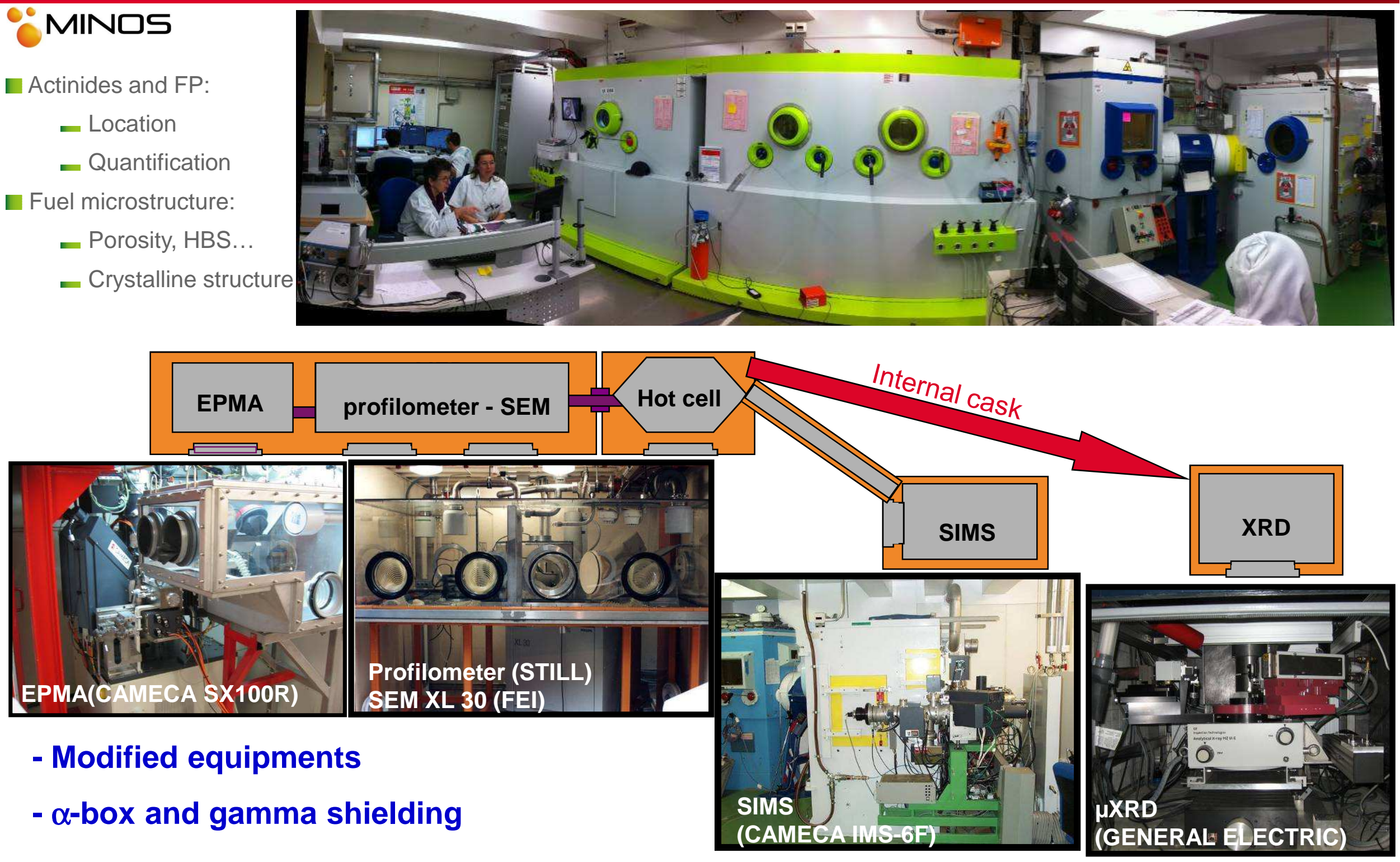

CEA-DEN-CAD-DEC-SA3C

MINOS Workshop - December 5-7, 2012, CEA - INSTN Saclay, France 7 


\section{Cea Xenon analysis: Coupling SEM, EPMA and SIMS}

\section{MINDS}
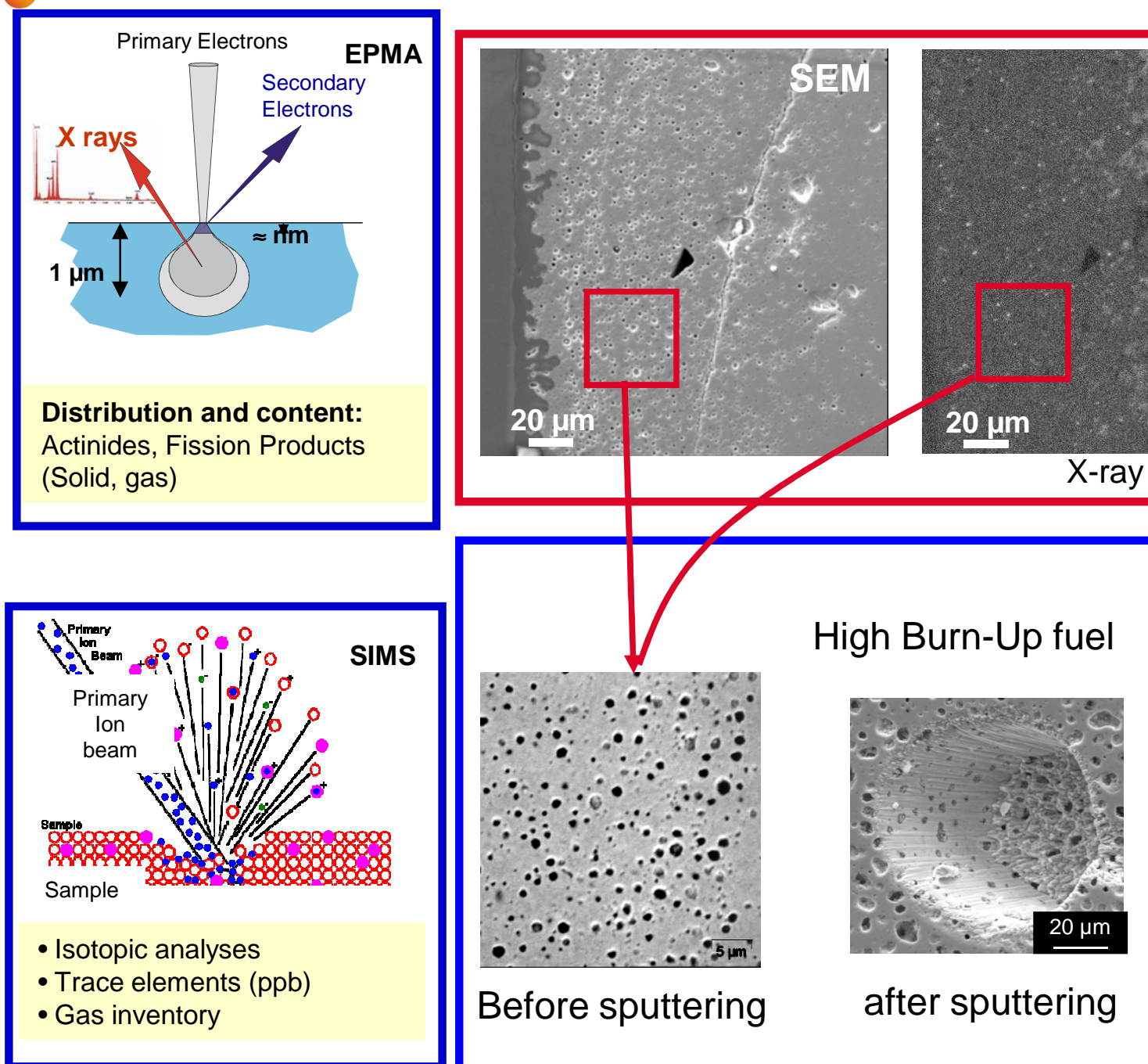

\section{Xe inventory}

- EPMA quantitative analysis

- Sample preparation effect (RIM, fuel center)

- In depth SIMS analysis

- SIMS to EPMA calibration

Actinides, Fission Products

Before sputtering

after sputtering

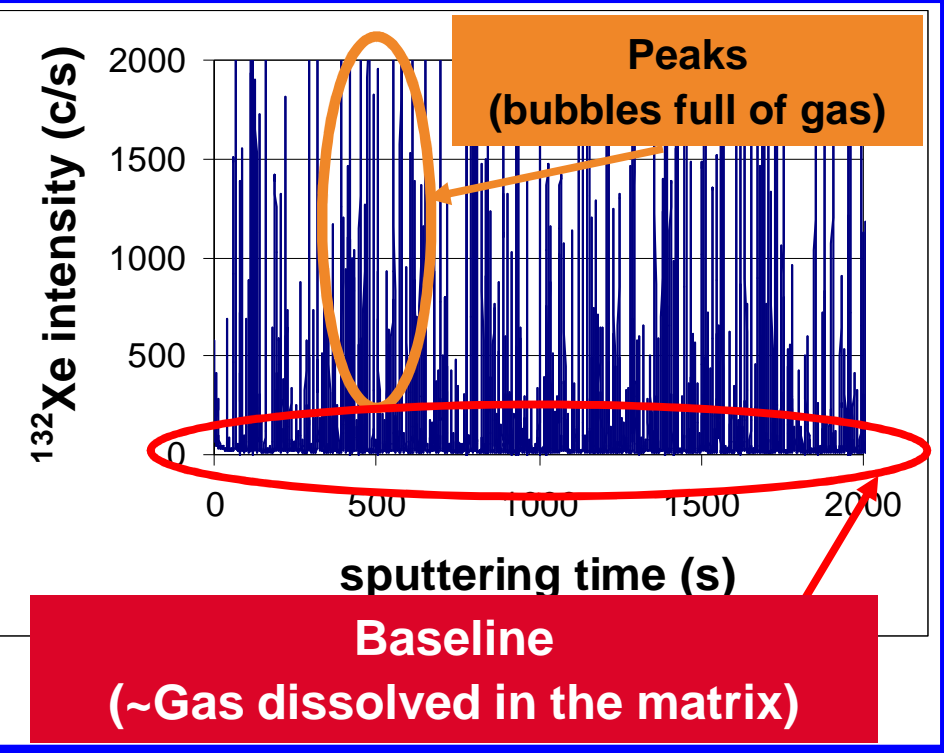




\section{cea Outline}

\section{MINDS}

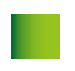

I PIE facilities

Fission gases behavior: nominal operating conditions

+

Fission gases behavior: simulated accidental conditions

口 


\section{Fission gas behavior: nominal operating conditions}

\section{MINDS}

\section{$67 \mathrm{GWd} / \mathrm{tU}$ high burn-up $\mathrm{UO}_{2}$ PWR fuel}

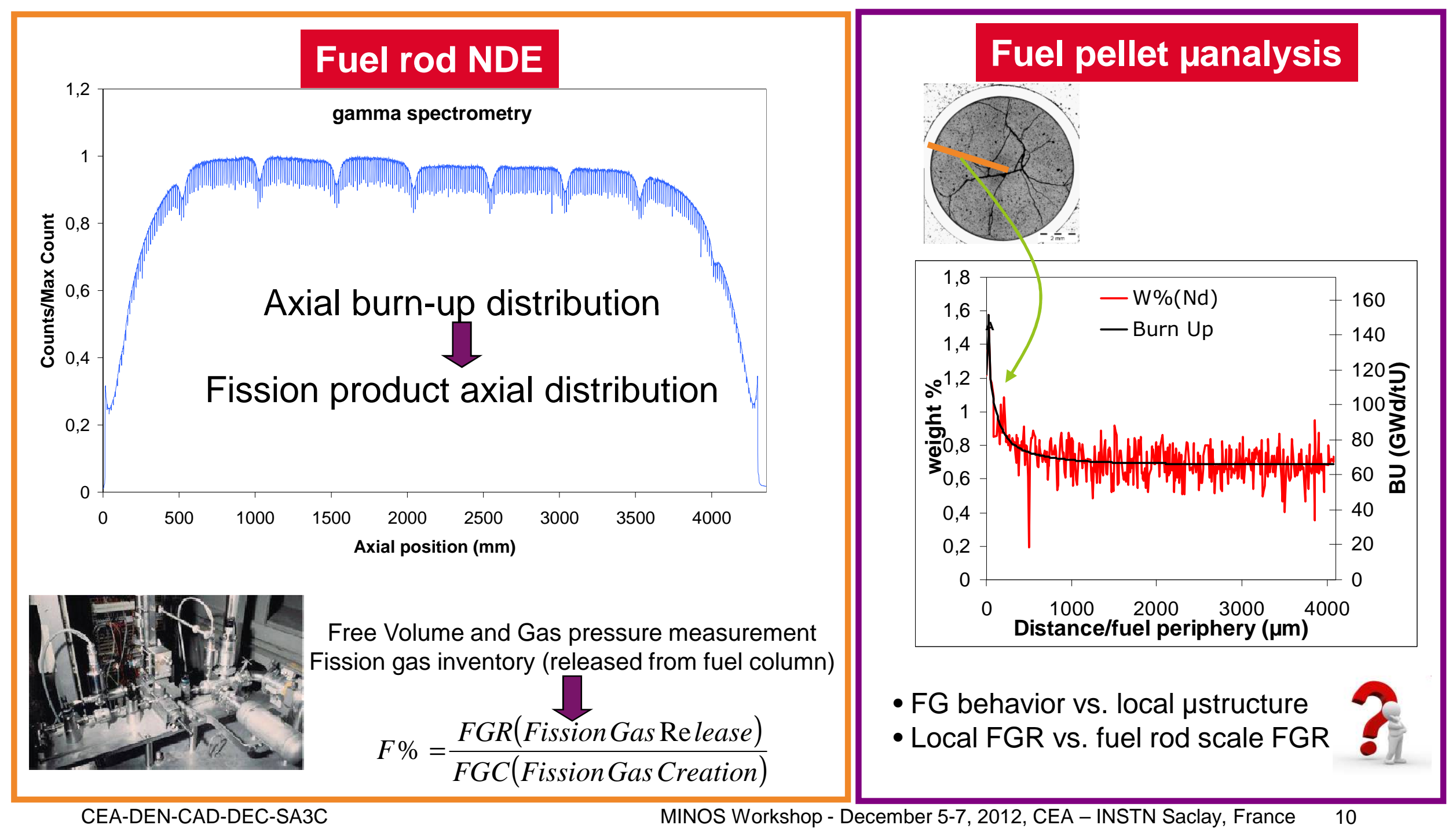




\section{Cla Fission gas: local behavior}

\section{MINDS Fuel periphery}

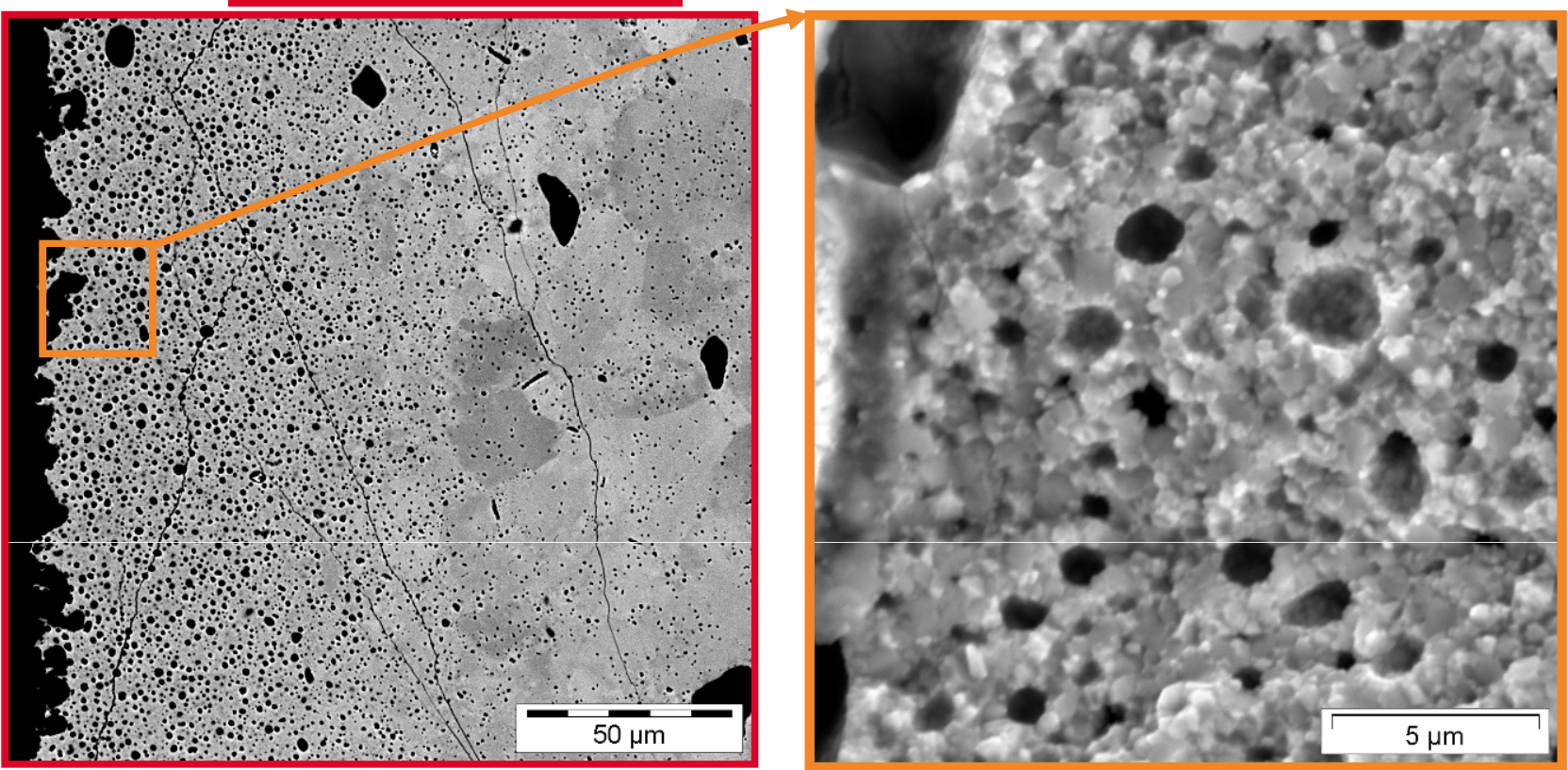

- SEM:

- High density of gas

bubbles

- RIM structure

- EPMA Xe profile:

- << creation

- FGR ?

- SIMS depth profile:

- Xe mainly precipitated

- Baseline (precipitated in nano bubbles) $\approx$ EPMA

- total inventory $\approx$ creation

- No signíficant FGR
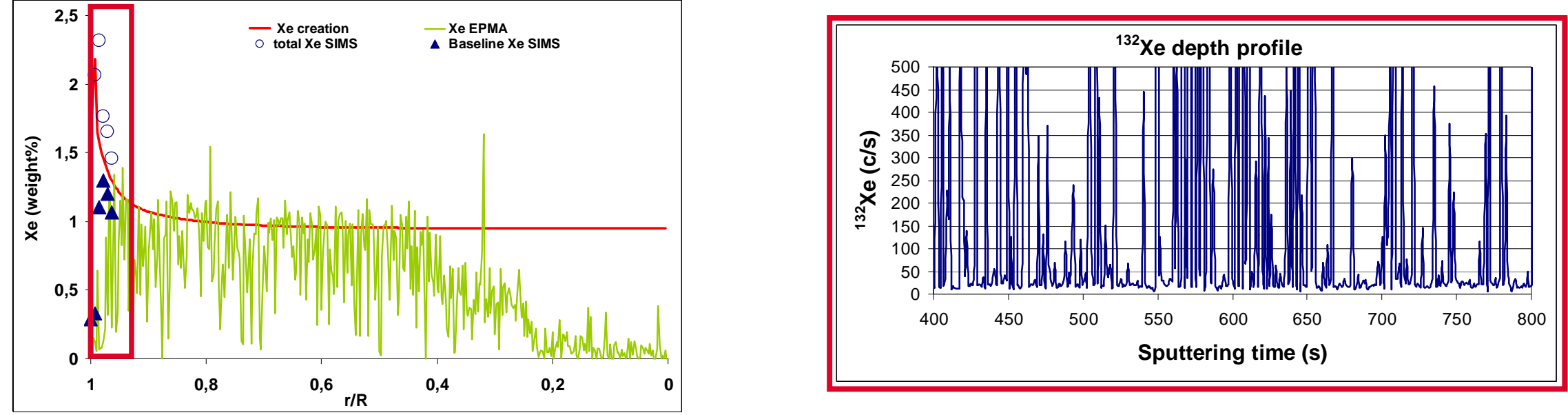

CEA-DEN-CAD-DEC-SA3C 


\section{Cea Fission gas: local behavior}

\section{¿MINaS Fuel center}

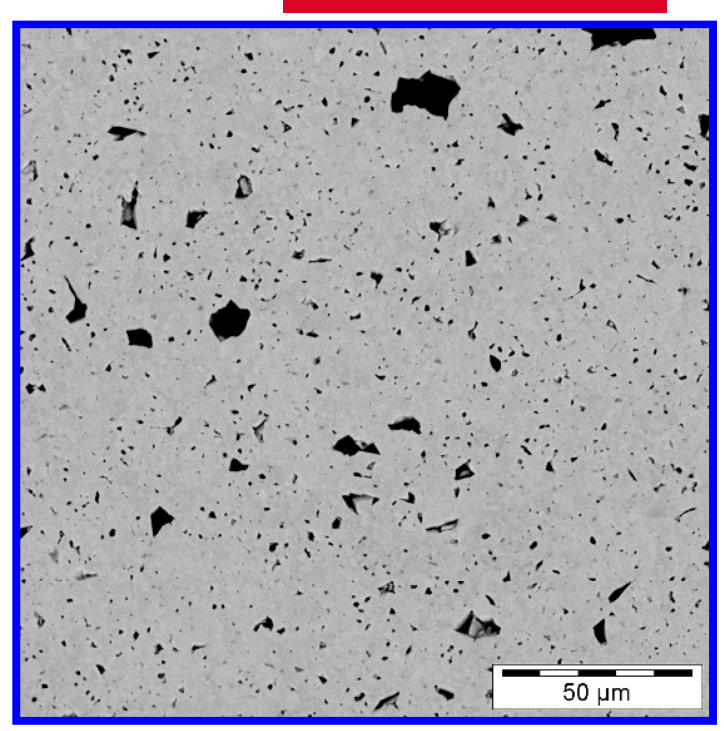

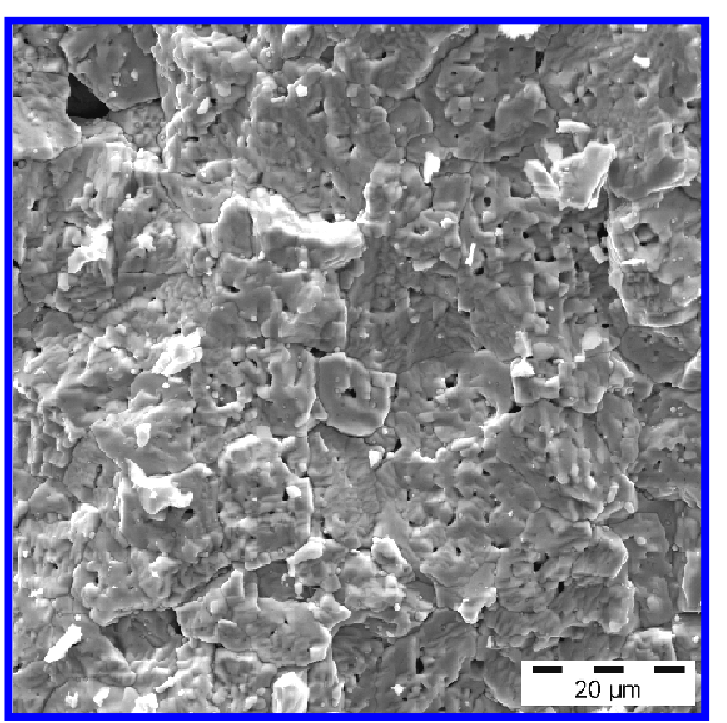

- SEM:

- High density of gas

bubbles

- EPMA Xe profile:

- $<<$ creation

- FGR ?

- SIMS depth profile:

- Part of Xe precipitated

- nano-precipitated $\mathrm{Xe} \approx$

EPMA

- total inventory < creation

- Local FGR
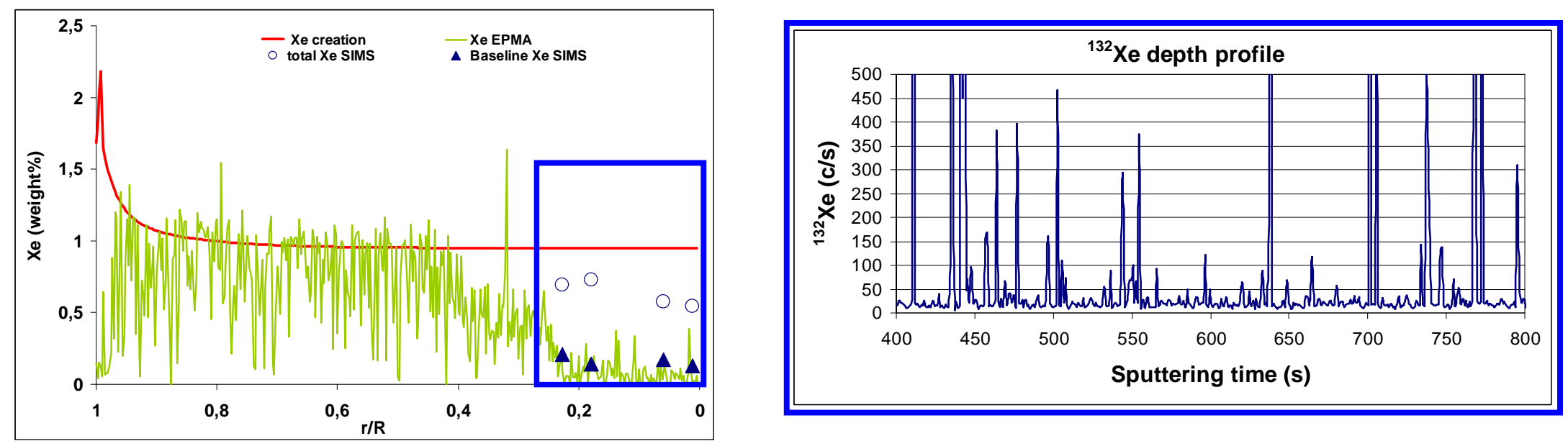


\section{Quantitative analysis}

\section{MINDS}

\section{Local/Total FG release}

Fuel rod FG release: 6,2\% $(\mathrm{BU} \approx 67 \mathrm{GWd} / \mathrm{tU})$

Local FG release: $\approx 8-10 \%$ (local $\mathrm{BU} \approx 73 \mathrm{GWd} / \mathrm{tU}$ )

Fission Gas bubble pressure

\begin{tabular}{|c|c|}
\hline W\% Xe in bubbles & RIM \\
\hline $\begin{array}{c}\text { S\% Bubbles } \\
(<3,5 \mu \mathrm{m})\end{array}$ & 14 \\
\hline $\begin{array}{c}\text { At. Vol. } \\
\left(\AA^{3} \cdot \mathrm{at}^{-1}\right)\end{array}$ & 141 \\
\hline Bubble pressure $(\mathrm{MPa})[4]$ & $\begin{array}{l}13(300 \mathrm{~K}) \\
84(650 \mathrm{~K})\end{array}$ \\
\hline
\end{tabular}

[4]: C. Ronchi, JNM, 96 (1981) 314-328

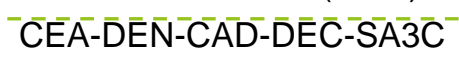

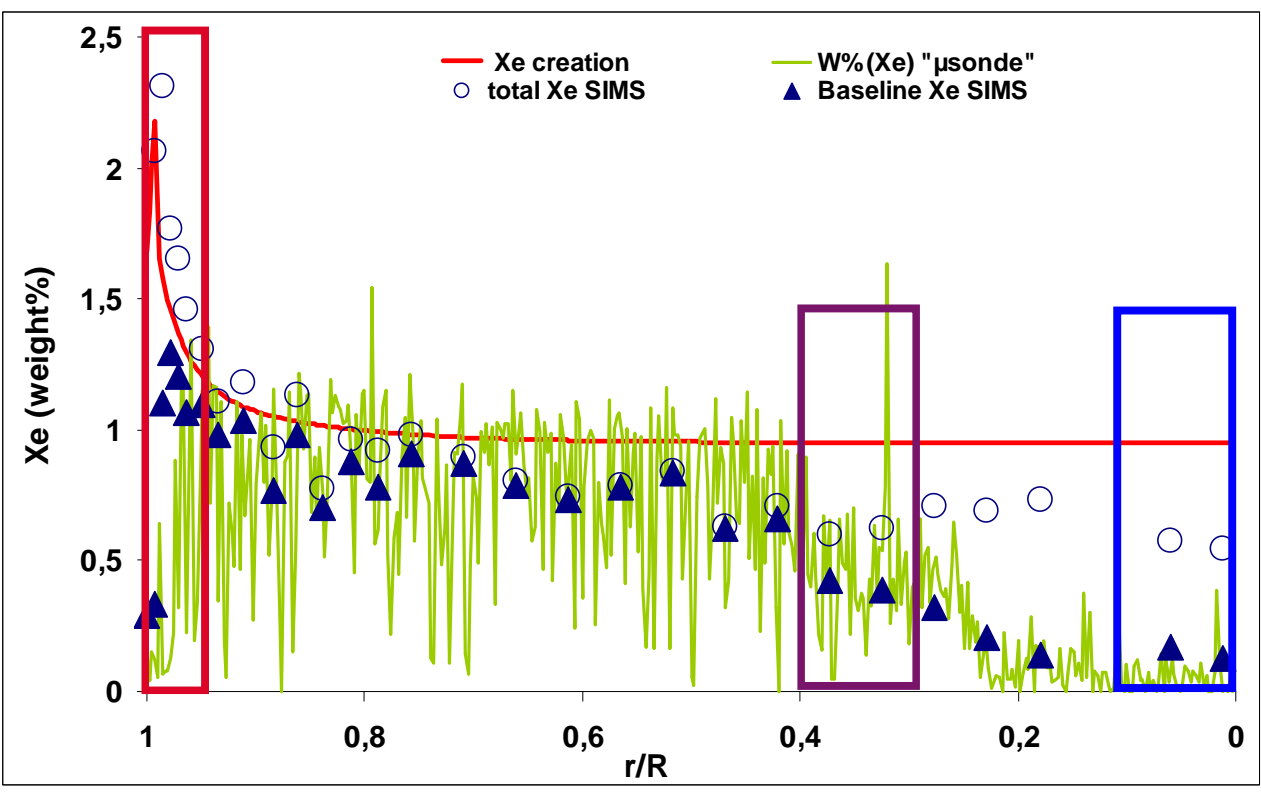

\begin{tabular}{|c|c|}
\hline $0.3-0,4 \mathrm{r} / \mathrm{R}$ & Center \\
\hline 0.2 & 0.4 \\
\hline 1.8 & 3.5 \\
\hline 182 & 172 \\
\hline $8(300 \mathrm{~K})$ & $8(300 \mathrm{~K})$ \\
$130(1220 \mathrm{~K})$ & $150(1280 \mathrm{~K})$ \\
\hline
\end{tabular}

MINOS Workshop - December 5-7, 2012, CEA - INSTN Saclay, France 


\section{cea Outline}

MINDS

Fission gases behavior: simulated accidental conditions 


\section{Cea Fission gas behavior: simulated accidental conditions}

\section{MINDS}

63 GWd/tU high burn-up UO $\mathrm{OWR}_{2}$ fuel [5]

- Lost Of Cooling Accident (LOCA) simulation

ש On-line fission gas $(85 \mathrm{Kr})$ release

- Overall release

- Temperature dependant bursts

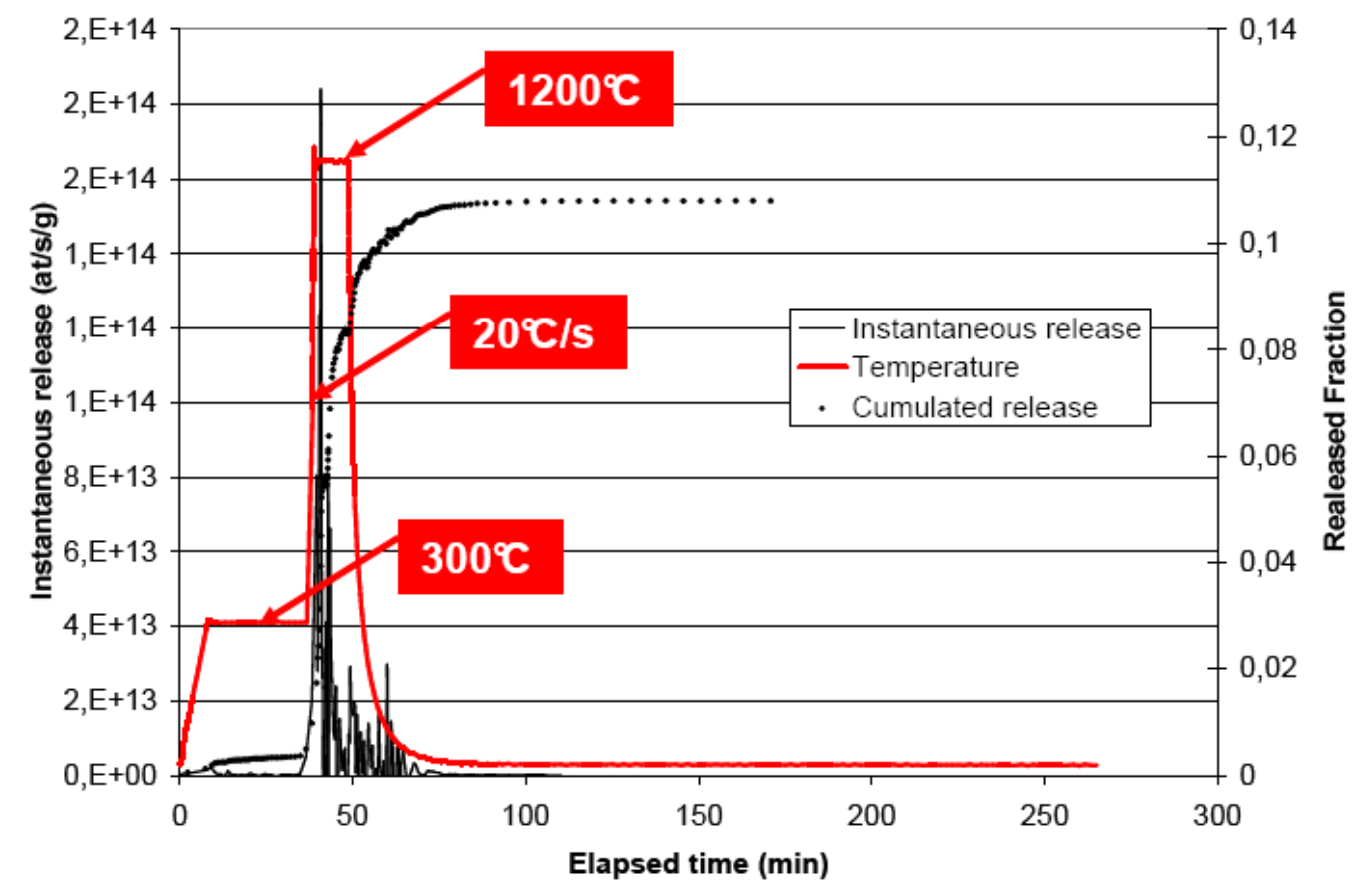




\section{Fission gas behavior: simulated accidental conditions}

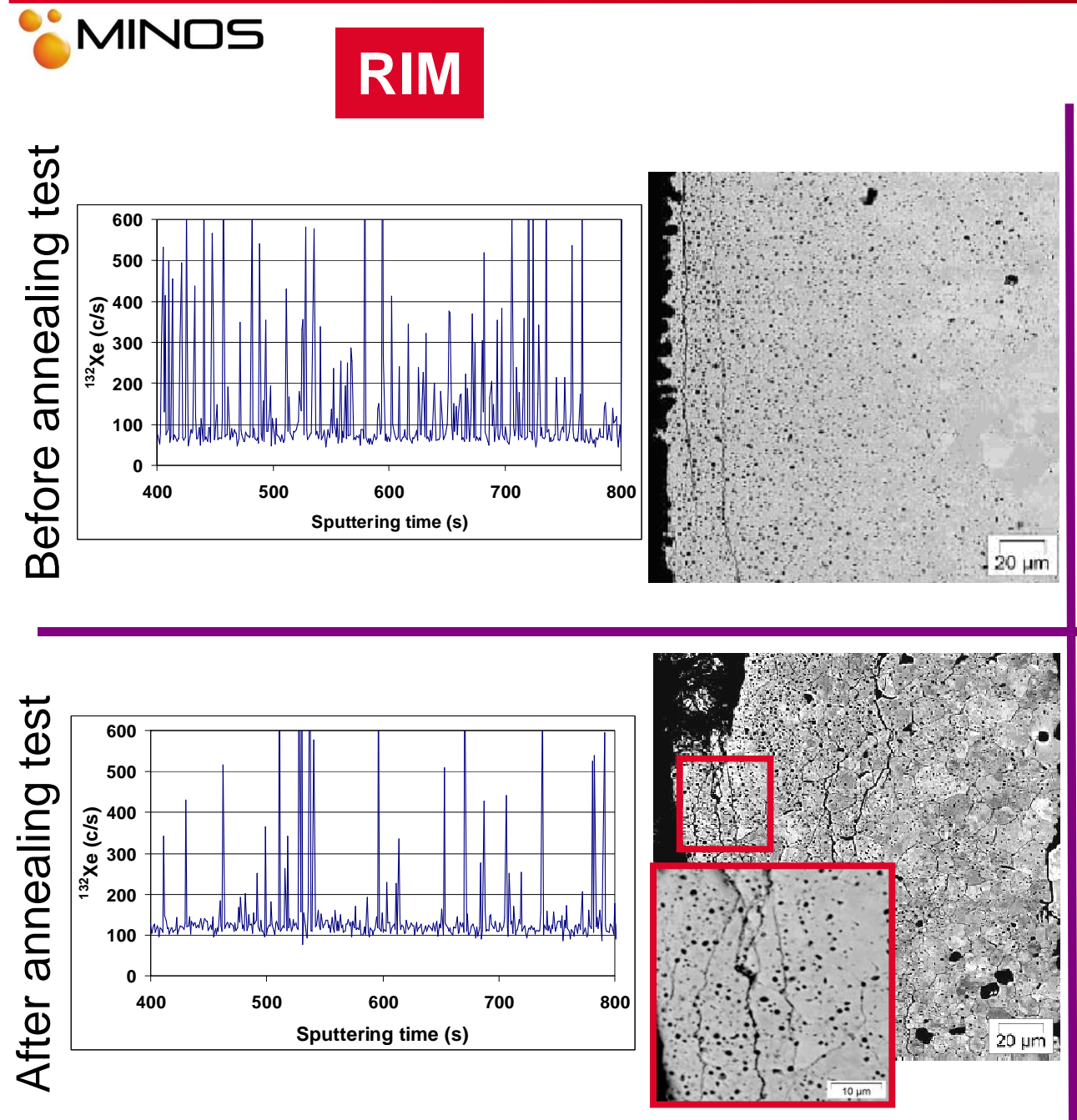

- RIM cracking

- No significant evolution of nano-precipitated gas

- Sharp decrease of Xe bubbles CEA-DEN-CAD-DEC-SA3C

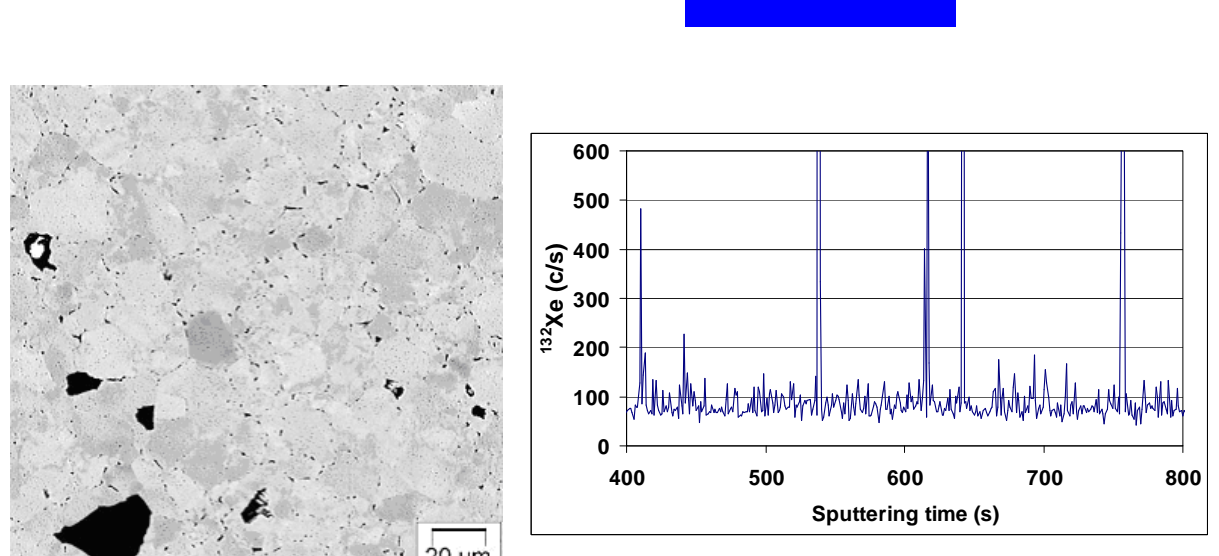

Center

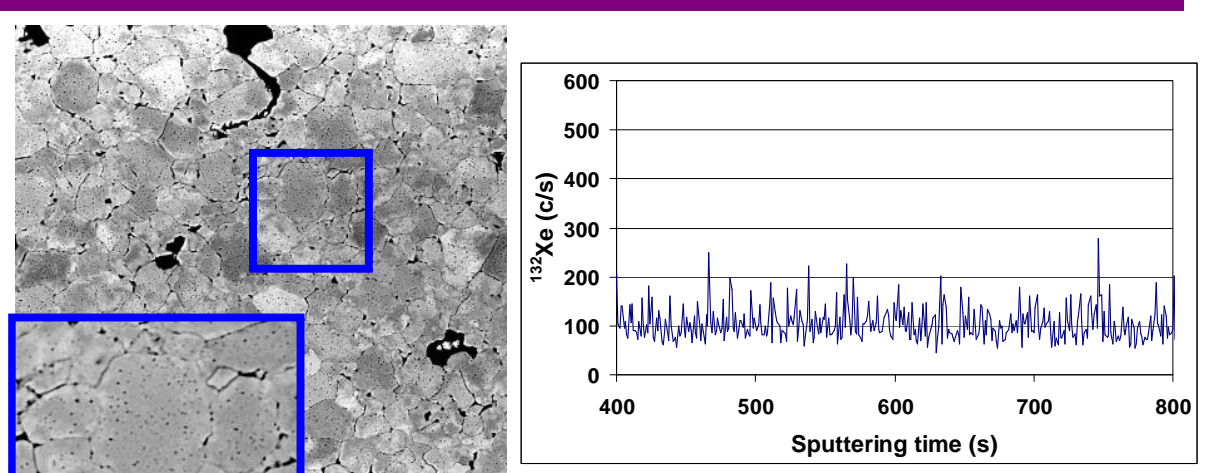

- Grain boundaries opening

- no significant evolution of nano-precipitated gas

- No SIMS bubble detection

MINOS Workshop - December 5-7, 2012, CEA - INSTN Saclay, France 


\section{Fission gas behavior: simulated accidental conditions}

\section{MIN口S}

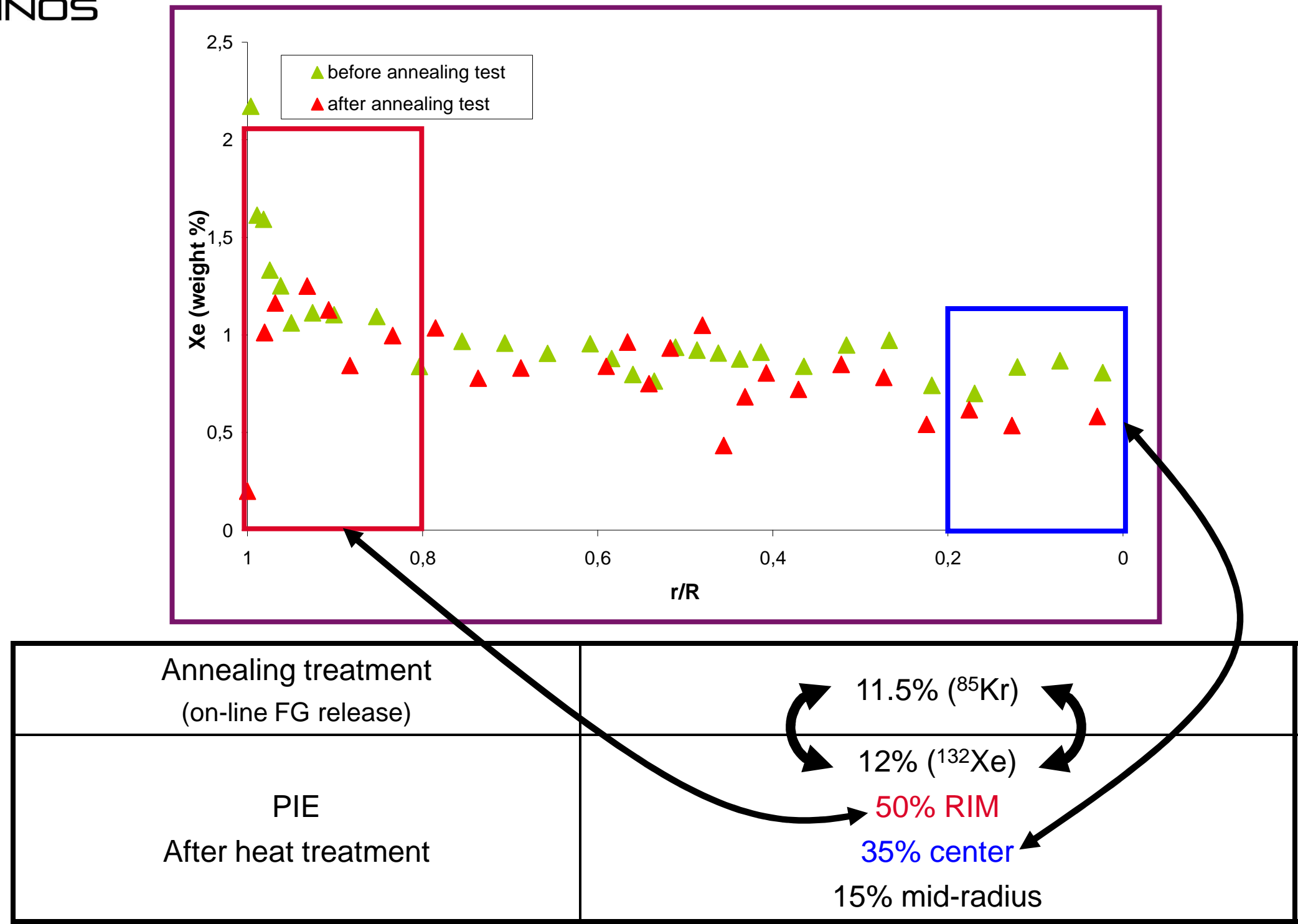




\section{Summary}

\section{MIN口S}

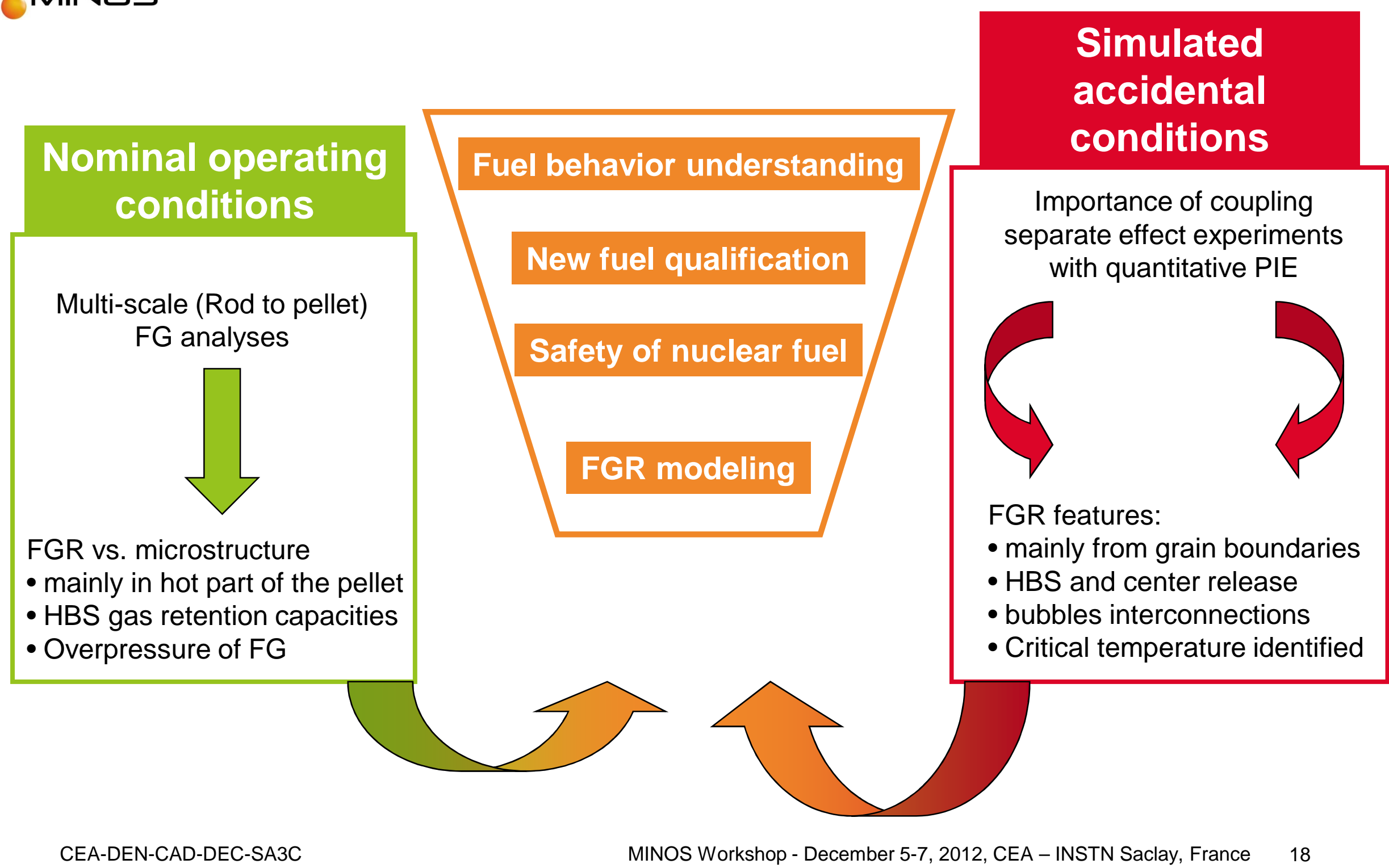




\section{Cea Further projects:}

\section{MINDS}

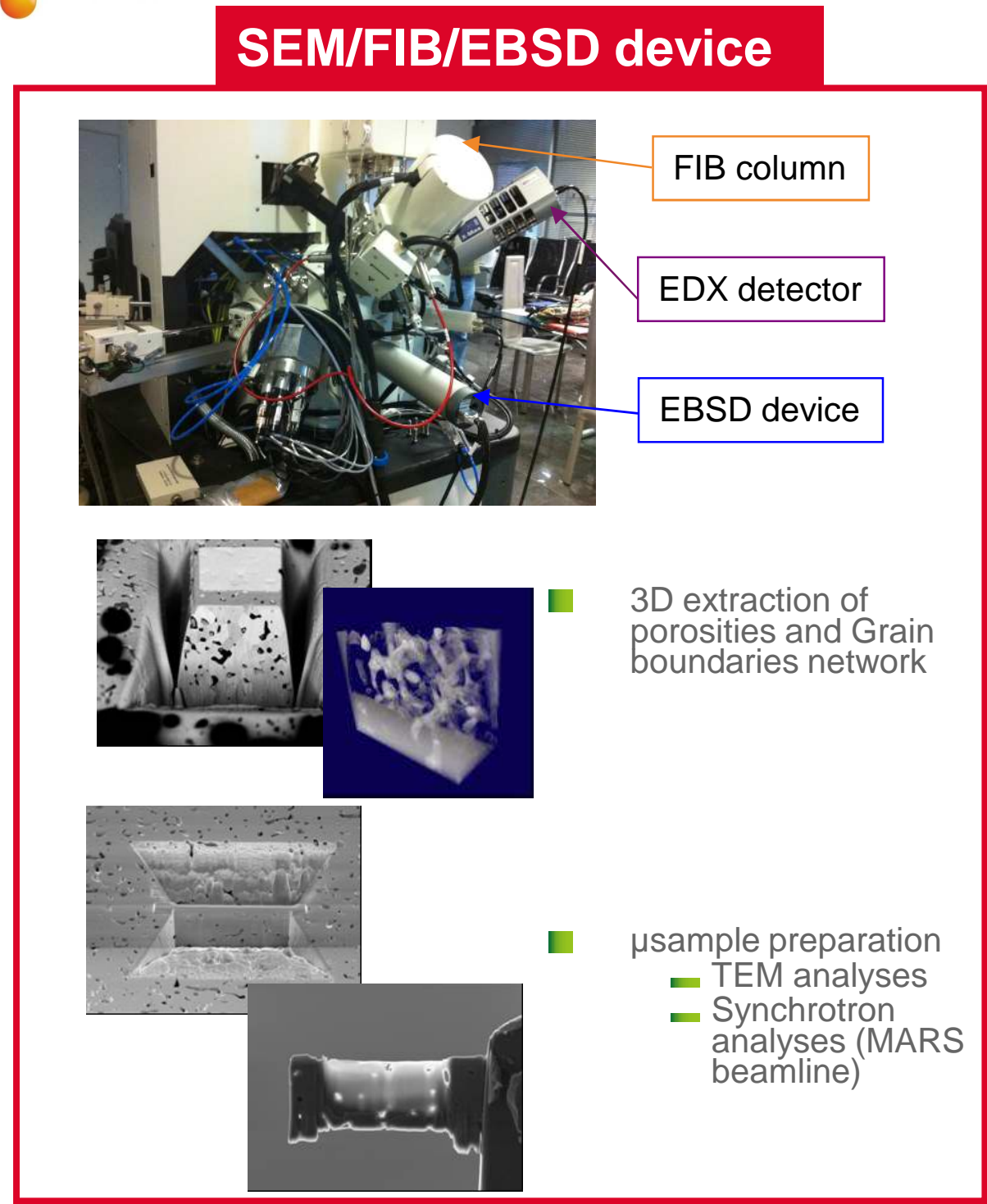

\section{High pressure annealing loop}

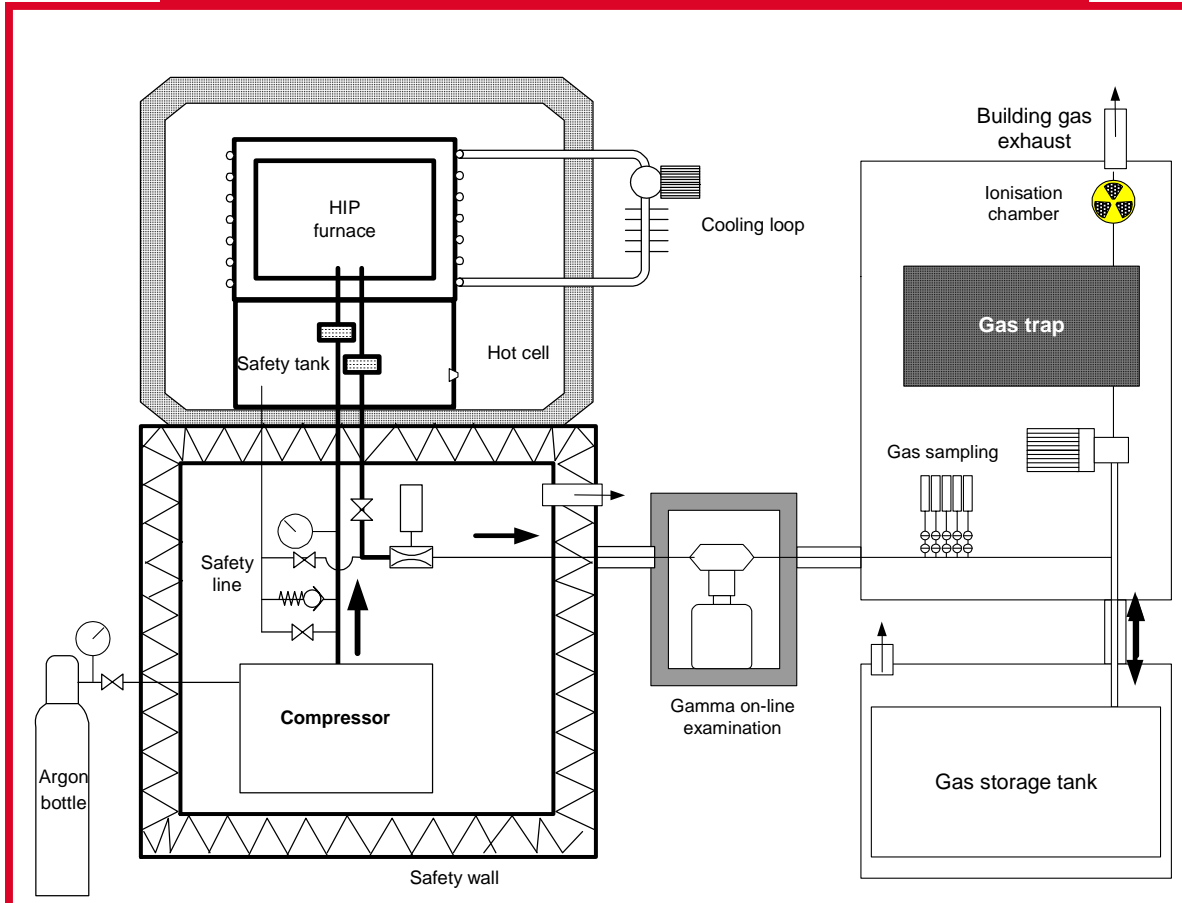

I Impact of fuel rod internal pressure on FGR

E Max Temperature/pressure: $1600^{\circ} \mathrm{C} / 1600$ bars

- Fission gas behavior: nominal operating conditions

- Standard fuel sample, one pellet

- Main analytical capability: online gamma spectrometry 


\section{Thank you for your attention}

Contribution:

I. Aubrun, Ph. Bienvenu, S. Clément, B. Lacroix, J. Lamontagne, B. Petitprez, C. Pozo

Th. Blay, E. Brochard, P. Delion, I. Roure 